\title{
Characteristics of polypoid lesions in patients undergoing microsurgery of the larynx
}

\author{
Jorge Massaaki Ido Filho', Bettina Carvalho², Flavio Massao Mizoguchi', Guilherme Simas do Amaral Catani', \\ Evaldo Dacheux de Macedo Filho', Osvaldo Malafaia ${ }^{4}$, Henrique Jorge Stahlke Jr. ${ }^{5}$
}

\author{
1) ENT doctor recognized by ABORL (Physician at Hospital IPO and at the ENT Department of HC/UFPR.) \\ 2) ENT doctor recognized by ABORL (Fellow at Hospital IPO) \\ 3) ENT doctor recognized by ABORL (Physician at Hospital IPO) \\ 4) $\mathrm{PhD}$ in Medical Anatomy (1976). Professor associated with the postgraduate program in Surgical Principles at the Faculdade Evangelica do Parana \\ 5) $\mathrm{PhD}$ in Clinical Surgery in the postgraduate program at UFPR (2002).Professor and Coordinator of Vascular Surgery at HC/UFPR \\ Institution: Hospital IPO \\ Curitiba / PR - Brazil \\ Mailin address: Hospital IPO - Dra Bettina Carvalho - Av. República Argentina, 2069 - Água Verde - Curitiba / PR - Brazil - Zip Code: $80620-010$ - Telephone: \\ (+55 41) 3314-1500 - http://ipo.com.br - E-mail: contato@ipo.com.br \\ Article received on January $24^{\text {th }}, 2013$. Article accepted on March $19^{\text {th }}, 2013$
}

\section{SUMMARY}

Introduction: Dysphonia is the main symptom of lesions that affect the vocal tract. Many of those lesions may require surgical treatment. Polyps are one of the most common forms of vocal cord lesions and the most prevalent indication for laryngeal microsurgery. There are different types of polyps, and their different characteristics can indicate different prognosis and treatments. Aim: To conduct a comparative study of polypoid lesions (angiomatous and gelatinous) in patients undergoing laryngeal microsurgery via an electronic protocol.

Method: We prospectively evaluated 93 patients diagnosed with vocal fold polyps; the polyps were classified as angiomatous or gelatinous.

Results: In total, 93 patients undergoing laryngeal microsurgery were diagnosed with vocal fold polyps. Of these, 63 (64.74\%) had angiomatous and 30 (32.26\%) gelatinous polyps. Most patients with angiomatous polyps were men; their polyps were frequently of medium size, positioned in the middle third of the vocal fold, and accompanied by minimal structural alterations (MSA). In contrast, the majority of patients with gelatinous polyps were women; their polyps were smaller, positioned in the middle and posterior third of the vocal fold, and were not accompanied by MSA. Both types of polyps were more frequently located on the right vocal fold.

Conclusion: Angiomatous polyps were more frequently encountered than gelatinous polyps. In addition, correlations between polyp type and sex, polyp size, position, location, and the presence of MSA were observed. Different surgical techniques were used, but the postoperative results were similar and satisfactory after speech therapy.

Keywords: Polyps; Vocal Cords; Microsurgery.

\section{INTRODUCTION}

Dysphonia is the main symptom of lesions that affect the vocal tract. More than $50 \%$ of individuals with voice disorders have benign alterations of the vocal fold mucosa. Polyps are one of the most frequent vocal cord lesions and are the most prevalent indication for laryngeal microsurgery. Like nodules, polyps are caused by overuse and abuse of the voice (1), although they may also occur as a result of a single traumatic incident $(2,3)$. Trauma can affect the superficial vases of the lamina propria causing the liquids within to overflow, displacing the epithelial layer and inducing scarring due to the deposition of fibrin and vascular proliferation. Depending on the type of vascularization, polyps are classified as angiomatous or hemorrhagic if accompanied by vascularity or as hyaline or gelatinous in the absence of vascularization.
The clinical picture is characterized by dysphonia related to intense vocal use, and is generally well-defined and recognized by the patient. The dysphonia is constant, and may progressively worsen. The voice presents as hoarse and breathy; sometimes it can be rough and, infrequently, diplophonic. A diagnosis is made by assessing the clinical history, and by perceptive analysis and observation of the phonatory system, which includes assessments of the phonatory posture adopted, articulation, and attitude. Laryngoscopy with or without stroboscopy can confirm the diagnosis. Treatment of vocal polyps is essentially surgical (4).

Vocal polyps can have many presentations and characteristics, and the aim of our study was to identify the characteristics of the polyps found in our population.

The objective of this study was to analyze and 
compare the features of polyps (intrinsic characteristics, associated lesions, and treatment outcomes) from patients undergoing laryngeal surgery at our hospital.

\section{Methods}

This prospective study was conducted from February 2010 to February 2011 using an electronic computerized protocol once the approval of the ethics committee had been obtained (CAEE :0286.0208.000-11). We used the SINPE (C) electronic protocol with the SINPE(C) Analyzer for data analysis $(5,6,7)$. The protocol-based software program is capable of storing and manipulating data on a theoretical basis. The SINPE@ Analyzer module is used to create reports, graphs, and statistics summarizing the main findings. A specific protocol for laryngeal disorders among the master ENT protocol available in SINPE was used for the analysis; only patients diagnosed with vocal fold polyps were analyzed.

In total, 245 microsurgeries of the larynx were performed in our Hospital during the study period. The inclusion criteria were as follows: a diagnosis of polyps, clinical laryngoscopy, and intraoperative confirmation of the diagnosis by anatomopathology. Exclusion criteria were as follows: a diagnosis of infiltrative processes or storage disease (vocal polyps not identified upon anatomopathologic examination).

Of the 245 patients who underwent surgery during the study period, 93 (36.61\% of lesions) with vocal polyps and an indication for microsurgery were evaluated. These 93 patients were classified into 2 groups according to the physical and histological characteristics of the lesions: (a) those with angiomatous polyps $(n=63,67.75 \%)$ and $(b)$ those with gelatinous polyps $(n=30,32.25 \%)$. Comparisons between the 2 groups were made according to 12 anatomic and surgical parameters based on the polyp characteristics. Parameters 1-8 refer to the intrinsic characteristics of the polyps (Table 1), parameters 9 and 10 refer to polypassociated lesions (Table 2), and parameters 11 and 12 refer to the treatment strategy (Table 3).

Table I. Polyp Intrinsic Characteristics.

\begin{tabular}{|c|c|}
\hline Parameter & Description \\
\hline I. Sex & male orfemale \\
\hline \multicolumn{2}{|l|}{ 2. Age } \\
\hline 3. Size & $\begin{array}{l}\text { a) small: the polyp takes up one-third of the vocal fold } \\
\text { b) medium: the polyp occupies two-thirds of the vocal fold } \\
\text { c) large: the polyp fills more than two-thirds of the vocal fold }\end{array}$ \\
\hline 4.Implantation & $\begin{array}{l}\text { a) sessile: the lesion is considered sessile if it has a wide base } \\
\text { b) pedunculated: the polyp presenting small implantation with elevation of its base (with a stalk or peduncle) }\end{array}$ \\
\hline 5. Lobulation & $\begin{array}{l}\text { a) unilobulated: only one lobulation } \\
\text { b) bilobulated: two lobulations } \\
\text { c) multilobulated: many lobulations }\end{array}$ \\
\hline 6. Position & $\begin{array}{l}\text { a) anterior third: the polyp is within the anterior third of the vocal fold } \\
\text { b) middle third: the polyp is within the middle third of the vocal fold } \\
\text { c) posterior third: the polyp is within the posterior third of the vocal fold }\end{array}$ \\
\hline 7. Location & $\begin{array}{l}\text { a) free edge: the polyp is located at the free edge of the vocal fold } \\
\text { b) upper edge: the polyp is located at the top edge of the vocal fold } \\
\text { c) lower edge: the polyp is located on the bottom edge of the vocal fold } \\
\text { d) more than one location: the polyp covers various sites (e.g., transglottic polyp) }\end{array}$ \\
\hline $\begin{array}{l}\text { 8. Location of polyp } \\
\text { on vocal fold }\end{array}$ & $\begin{array}{l}\text { a) right vocal fold } \\
\text { b) left vocal cord } \\
\text { c) bilateral: polyp on both the right and left folds }\end{array}$ \\
\hline
\end{tabular}

Table 2. Associated lesions.

\begin{tabular}{|c|c|c|c|}
\hline Parameter & Description & & \\
\hline 9. Presence of associated lesions and their type & $\begin{array}{l}\text { a) nodular reaction } \\
\text { b) varicosity } \\
\text { c) stria major }\end{array}$ & $\begin{array}{l}\text { d) groove bag } \\
\text { e) stria minor } \\
\text { f) intracordal cyst }\end{array}$ & $\begin{array}{l}\text { g) mucous cyst } \\
\text { h) mucosa bridge } \\
\text { i) microdiaphragm }\end{array}$ \\
\hline 10. Associated lesions in relation to the vocal fold & $\begin{array}{l}\text { a) ipsilateral-on the } \\
\text { b) contralateral-on }\end{array}$ & $\begin{array}{l}\text { vocal fold polyp } \\
\text { site vocal fold polyp }\end{array}$ & \\
\hline
\end{tabular}


Table 3. Treatment.

\begin{tabular}{ll}
\hline Parameter & Description \\
\hline $\begin{array}{ll}\text { II. Surgical technique a) polypgrip + microscissors (holding the polyp and performing resection with microscissors) } \\
\text { b) medial microflap + microscissors (microbisturi incision, creation of a medial microflap, and resection with } \\
\text { microscissors) }\end{array}$ \\
$\begin{array}{ll}\text { I2. Evolution of } & \text { a)optimal: satisfactory treatment } \\
\text { Speechtherapy } & \text { b) poor: unsatisfactory treatment }\end{array}$
\end{tabular}

Table 4. Comparative analysis of internal characteristics of angiomatous and gelatinous polyps.

\begin{tabular}{|c|c|c|c|}
\hline Parameter & $\begin{array}{l}\text { Angiomatous } \\
\mathrm{n}=63(64.74 \%)\end{array}$ & $\begin{array}{l}\text { Gelatinous } \\
n=30(32.26 \%)\end{array}$ & $p<0.05$ \\
\hline \multicolumn{4}{|l|}{ I.Sex } \\
\hline Male & $4 \mid(65.08 \%)$ & 10 (33.33\%) & \multirow{3}{*}{$p=0.008$} \\
\hline Female & $22(34.92 \%)$ & $20(66.67 \%)$ & \\
\hline 2. Age & $4 I-60$ years $(49.21 \%)$ & $20-40$ years $(46.67 \%)$ & \\
\hline 3. Size & $\begin{array}{l}\text { Medium } \\
43(68.25 \%)\end{array}$ & $\begin{array}{l}\text { Small } \\
17(56.67 \%)\end{array}$ & \multirow[t]{2}{*}{$p=0.001$} \\
\hline 4. Implantation & $\begin{array}{l}\text { Pedunculated } \\
35(55.56 \%)\end{array}$ & $\begin{array}{l}\text { Sessile } \\
19(63.33 \%)\end{array}$ & \\
\hline 5. Lobulation & $\begin{array}{l}\text { Unilobulated } \\
53 \text { (84.13\%) }\end{array}$ & $\begin{array}{l}\text { Unilobulated } \\
26 \text { (86.67\%) }\end{array}$ & \multirow{4}{*}{$\begin{array}{l}p=0.02 \\
p=0.03\end{array}$} \\
\hline \multicolumn{4}{|l|}{ 6. Position } \\
\hline $\begin{array}{l}\text { anteriorthird } \\
\text { middlethird } \\
\text { posteriorthird }\end{array}$ & $\begin{array}{l}25(35 . / 1 \%) \\
36(51.43 \%) \\
9(12.86 \%)\end{array}$ & $\begin{array}{l}8(26.6 / \%) \\
||(36.67 \%) \\
||(36.67 \%)\end{array}$ & \\
\hline *Number of positions: & 34 (53.96\%) & $24(80 \%)$ & \\
\hline $\begin{array}{l}\text { One } \\
\text { Morethanone }\end{array}$ & $29(46,04 \%)$ & $6(20 \%)$ & \\
\hline 7. Location & $\begin{array}{l}\text { Free edge } \\
42(66.67 \%)\end{array}$ & $\begin{array}{l}\text { Free edge } \\
20(66.67 \%)\end{array}$ & \\
\hline \multicolumn{4}{|l|}{$\begin{array}{l}\text { 8. Location of polypon } \\
\text { vocal fold: }\end{array}$} \\
\hline right & $39(61.9 \%)$ & $14(46.67 \%)$ & \multirow{3}{*}{$p=0.009$} \\
\hline left & 22 (34.92\%) & $9(30 \%)$ & \\
\hline bilateral & $2(3.17 \%)$ & 7 (23.33\%) & \\
\hline
\end{tabular}

The protocols were performed on the day before surgery after the pre-anesthetic consultation, and supplemented during the postoperative follow-up. Endolaryngeal microsurgeries were performed in the operating room of the same institution using suspension laryngoscopy (SL) by 3 doctors from the Laryngology and Voice Service department.

During SL, the vocal folds were subject to visual inspection and palpation with delicate microforceps. The microsurgical technique used depended on the preoperative evaluation and its confirmation during surgery.

Statistical analyses were performed using the Chisquare test to compare the variables discussed above, and the significance level was set at $p<0.05$.

\section{RESULTS}

All 93 patients underwent laryngeal surgery due to a diagnosis of polyps of the vocal folds during the period February 2010 to February 2011. Of these, 63 (64.74\%) had angiomatous and 30 (32.26\%) had gelatinous polyps. Regarding sex, 51 were male and 42 female. Their age ranged from 20 to 80 years. The distribution according to the 12 parameters for each type of polyp is shown in Tables 4, 5, and 6 .

\section{DISCUSSION}

Benign lesions of the vocal folds represent a 
Table 5. Comparative analysis of parameters relating to lesions associated with angiomatous and gelatinous polyps.

\begin{tabular}{|c|c|c|c|}
\hline Parameter & $\begin{array}{l}\text { Angiomatous } \\
n=63(64.74 \%)\end{array}$ & $\begin{array}{l}\text { Gelatinous } \\
n=30(32.26 \%)\end{array}$ & $p<0.05$ \\
\hline \multicolumn{3}{|l|}{ 9. Associated lesions } & \multirow[t]{15}{*}{$p=0.02$} \\
\hline a) nodular reaction & $26(44.83 \%)$ & $13(65 \%)$ & \\
\hline b) varicosity & $8(13.79 \%)$ & $4(20 \%)$ & \\
\hline c) stria major & $8(13.79 \%)$ & I (5\%) & \\
\hline d) groove bag & $4(6.9 \%)$ & 0 & \\
\hline e) stria minor & $3(5.17 \%)$ & 0 & \\
\hline f) intracordal cyst & $4(6.9 \%)$ & I (5\%) & \\
\hline g) mucouscyst & $2(3.45 \%)$ & | (5\%) & \\
\hline h) mucosabridge & $2(3,45 \%)$ & 0 & \\
\hline $\begin{array}{l}\text { i) microdiaphragm } \\
\text { * Presence of MSA }\end{array}$ & I ( $1.72 \%)$ & 0 & \\
\hline Present & $30(47,6 \mid \%)$ & $6(20 \%)$ & \\
\hline Absent & 33 (52.39\%) & $24(80 \%)$ & \\
\hline \multicolumn{3}{|l|}{$\begin{array}{l}\text { 10. Association of lesions } \\
\text { with the vocal fold: }\end{array}$} & \\
\hline |psilateral & 44 (69.84\%) & $27(76.67 \%)$ & \\
\hline Contralateral & $19(30.16 \%)$ & 7 (23.33\%) & \\
\hline
\end{tabular}

Table 6. Comparative analysis of parameters for treatment of angiomatous and gelatinous polyps.

\begin{tabular}{|c|c|c|c|}
\hline Parameter & $\begin{array}{l}\text { Angiomatous } \\
n=63(64.74 \%)\end{array}$ & $\begin{array}{l}\text { Gelatinous } \\
n=30(32.26 \%)\end{array}$ & $p<0.05$ \\
\hline $\begin{array}{l}\text { 1. Surgicaltechnique } \\
\text { Grip + microscissors } \\
\text { Medial microflap+ microscissors }\end{array}$ & $\begin{array}{l}36(57.14 \%) \\
27(42.6 \%)\end{array}$ & $\begin{array}{l}12(40 \%) \\
18(60 \%)\end{array}$ & \\
\hline 12. Evolution of speech therapy & $\begin{array}{l}\text { Optimal } \\
56(88.89 \%)\end{array}$ & $\begin{array}{l}\text { Optimal } \\
28(93.33 \%)\end{array}$ & \\
\hline
\end{tabular}

significant problem for otolaryngologists because they are very common and require a multidisciplinary treatment approach. When such lesions do not respond to drug therapy and/or speech therapy, surgery is required with the aim of increasing phonatory function or establishing a histological diagnosis by biopsy $(8,9)$.

In our study, we found 93 (36.61\%) polyps among 245 patients with vocal fold lesions who underwent laryngeal surgery during the period from February 2010 to February 2011 in our Hospital. This was the most frequent diagnosis observed in this study, which supports the reports by Haas \& Doderlein, Mossallam, and Lehmann and Kleinsasser, who noted that polyps were the main indication for laryngeal microsurgery (10-13).

Angiomatous polyps were more common (63 patients, 64.74\%) than gelatinous polyps (30 patients, $32.26 \%$ ). In addition, we noticed a male predominance among patients with angiomatous polyps and a female predominance among those with gelatinous polyps. The
Chi-square test (significance level, $p=0.008$ ) showed that the type of polyp was dependent on sex. The male predominance of angiomatous polyps (65.08\%) is consistent with the findings reported in the literature $(3,14,15)$, but there was no male predominance of gelatinous polyps. Instead, these were more common in women (66.67\%), which is a similar finding to that obtained by Dailey, who reported a female incidence of $62 \%$ among patients with gelatinous polyps (16). This may be because women are more likely to seek medical advice than men. In addition, female patients with increased vocal fold mass have a lower pitch, which has a greater impact on the social life of these patients than is the case with male patients.

Regarding size, the statistical analysis demonstrated that the polyp size was dependent on type. Most angiomatous polyps were of medium size (68.25\%) whereas most gelatinous polyps were small (56.67\%) $(p=0.001)$. Angiomatous polyps were also found most frequently in the middle third of the vocal fold (51.43\%), whereas the 
gelatinous polyps tended to be found in the middle and posterior thirds of the fold ( $36.67 \%$ each) ( $p=0.02)$. Thus, the position of the polyp in the vocal fold was also dependent on type.

In our study, both angiomatous and gelatinous polyps were predominantly found on the right vocal fold $(p=0.009)$, and so there is also a relationship between polyp type and its location on the vocal fold. Eckley et al. reported similar findings (14), whereas Sakae et al. (17) reported that polyps were found in the left vocal fold in $53 \%$ of cases.

The presence of MSA occurred in $47.61 \%$ of patients with angiomatous polyps, in comparison with $20 \%$ of patients with gelatinous polyps $(p=0.02)$. There was thus also a correlation between polyp type and the presence of MSA (greater in angiomatous polyps). In Sakae et al.'s study (16), polyps were associated with MSA in $23.5 \%$ of patients.

Reaction nodular lesions were found in $41.26 \%$ of the patients with angiomatous polyps and $43.33 \%$ of the patients with gelatinous polyps. There was no statistical difference between the two groups ( $\mathrm{p}=$ 0.97). In Eckley et al.'s study (14), $37 \%$ of patients had reaction lesions, confirming the suspicion that the impact of the polyp on the healthy vocal fold can cause long-term alterations in the epithelial layer of the contralateral vocal fold $(14,18)$.

Regarding the MSA, stria were the most frequently encountered lesions (49.9\%) in angiomatous polyps, whereas varicosity was predominant in gelatinous polyps (66.66\%). In Eckley et al.'s study (14), stria were the most frequently encountered MSA (70\%).

In our study, the patients underwent larynx surgery with SL, which led to considerable improvement in voice quality and the remission of other symptoms. The surgical technique most commonly used for angiomatous polyps is to grab the polyp and resect it with a microscissors (57.14\%). For gelatinous polyps, the main surgical technique is to create a medial microflap and then resect it with a microscissors (60\%). There was no difference in outcome when these techniques were compared.

After surgery, all of the patients underwent speech therapy with optimal developments in most cases (88.89 and $93.33 \%$ for those with angiomatous and gelatinous polyps, respectively). There is a consensus regarding the use of postoperative speech therapy and appropriate follow-up and successful outcome (9). We plan to undertake further analysis of the therapy outcomes in subsequent research projects.

\section{CONCLUSION}

In this study, angiomatous polyps were more frequently encountered than gelatinous polyps. There was a male predominance among patients with angiomatous polyps, and a female predominance among those with gelatinous polyps. Angiomatous polyps were more frequently associated with MSA. There was also a correlation between the size of the polyp, and its position and location in the vocal fold and the presence of MSA. Different surgical techniques were used, but the postoperative results were similar and satisfactory once the therapy was complete.

\section{REFERENCES}

1. Luchsinger R, Arnold GE. Voice-speech-language. Clinical communicology: It's Physiology and Pathology. Belmont: Wadsworth; 1965.

2. Martins RH, DefaveriJ, Domingues MA, de Albuquerque, Silva R.Vocal polyps: clinical, morphological, and immunohistochemical aspects. J Voice. 2011 Jan;25(1):98106.

3. Cielo CA, Finger LS, Rosa JC, Brancalioni AR. Lesões Organofuncionias do tipo nódulos, pólipos e edema de Reinke. CEFAC. 2011 Jul-Ago;13(4):735-48.

4. Sociedade Brasileira de Otorrinolaringologia (SBORL). Tratado de Otorrinolaringologia. São Paulo: Rocca; 2011.

5. Malafaia O, Borsato EP, Pinto JSP. Manual do usuário do SINPE@. Curitiba: UFPR; 2003.

6. Pinto JSP. Interface de viabilização de informações para o Sistema Integrado de Protocolos Eletrônicos [dissertation]. [Curitiba]: Universidade Federal do Paraná; 2005. 111 p.

7. Catani GSA, Carvalho B, Ido Filho JM, Macedo Filho ED, PintoJSP, Malafaia O, Stahlke Jr HJ. Proposed computerized protocol for epidemiological study of patients undergoing microsurgery of the larynx. Int. Arch. Otorhinolaryngol. 2012;16(3):346-52.

8. Woo P, Noordzij JP. Glottal area waveform analysis of benign vocal fold lesions before and after surgery. Ann Otol Rhinol Laryngol. 2000;109:441-6.

9. Cecatto S, Costa KS, Garcia RID, Haddad L, Angélico FV, Rapoport P. Pólipos de pregas vocais: aspectos clínicos e cirúrgicos. Rev Bras. Otorrinolaringol. 2002;68(4):5348. 
10. Haas E, Döderlein K. Endolaryngeal microsurgery. A report of our experiences in the years from 1966 to 1976. Laryngologie, Rhinologie, Otologie. 1978;57(3):235-42.

11. Mossallam I, Kotby MN, Ghaly AFEA. Histopathological aspects of benign vocal fold lesionsassociated with dysphonia. In: KirchnerJA, editor. Vocal Fold histipathology: A symposium. San Diego: College-Hill; 1986. p. 65-80.

12. Lehmann W, PampurikJ, Guyot JP. Laryngeal pathologies observed in microlaryngoscopy. ORL J Otorhinolaryngol Relat Spec. 1989;51(4):206-15.

13. Kleinsasser O. Microlaryngoscopy and endolaryngeal microsurgery. II: A review of 2500 cases. HNO. 1974;22(3):69-83.

14. Eckley CA, Swensson J, Duprat AC, Donati F, Costa HO. Incidência de alterações estruturais das pregas vocais associadas ao pólipo de prega vocal. Rev Bras Otorrinolaringol. 2008:74(4):508-11.
15. Neves BM, Neto JG, Pontes P. Diferenciação histopatológica e himunoistoquímica das alterações epiteliais no nódulo vocal em relação aos pólipos e ao edema de laringe. Rev Bras Otorrinolaringol. 2004;70(4):439-48.

16. Dailey SH, Spanou K, Zeitels SM. The evaluation of benign glottic lesions: rigid telescopic stroboscopy versus suspension microlaryngoscopy. J Voice. 2007;21(1):112-8.

17. Sakae FA, Sasaki F, Sennes LU, Tsuji DH, Imamura R. Pólipos de pregas vocais e alterações estruturais mínimas: lesões associadas? Rev Bras Otorrinolarigol. 2004:70(6):743-8.

18. Marcotullio D, Magliulo G, Pietrunti S, Suriano M. Exudative laryngeal diseases of Reinke's space: a clinicohistopathological framing. J Otolaryngol. 2002;31:376-80. 